\title{
Clinical Outcomes of Metachronous Gastric Cancer after Endoscopic Resection for Early Gastric Cancer
}

\author{
Jue Lie Kim ${ }^{1}$, Sang Gyun Kim ${ }^{1}$, Jung Kim² ${ }^{2}$ Jae Yong Park ${ }^{3}$, Hyo-Joon Yang ${ }^{4}$, Hyun Ju Kim ${ }^{5}$, and Hyunsoo Chung ${ }^{1}$ \\ ${ }^{1}$ Department of Internal Medicine and Liver Research Institute, Seoul National University College of Medicine, Seoul, ${ }^{2}$ Division of \\ Gastroenterology, Department of Internal Medicine, Armed Forces Capital Hospital, Seongnam, ${ }^{3}$ Division of Gastroenterology, Department of \\ Internal Medicine, Chung-Ang University Hospital, ${ }^{4}$ Division of Gastroenterology, Department of Internal Medicine and Gastrointestinal Cancer \\ Center, Kangbuk Samsung Hospital, Sungkyunkwan University School of Medicine, and ${ }^{5}$ Health Promotion Center, Seoul National University \\ Hospital, Seoul, Korea
}

\section{See editorial on page 145.}

Background/Aims: Patients treated with endoscopic submucosal dissection (ESD) for early gastric cancer (EGC) are at risk of developing metachronous gastric cancer (MGC). The aim of this study was to evaluate the clinical outcomes of MGC after ESD for EGC between the re-ESD and surgery groups. Methods: In total, data from 1,510 patients who underwent ESD for EGC from January 2005 to May 2014 were retrospectively reviewed, and data from 112 patients with MGC were analyzed according to the type of treatment, namely, re-ESD and surgery. The clinicopathological factors affecting the subsequent treatment and outcomes of MGC were evaluated. Results: The median duration to the development of MGC was 47 months. In multivariate analysis, lower body mass index (BMI) $(p=0.037)$ and multiplicity $(p=0.014)$ of index cases were significantly associated with subsequent surgery for MGC. In cases of MGC, a diffuse or mixed-type Lauren classification $(p=0.009)$, the depth of tumor mucosal invasion ( $p=0.001$ ), and an upper stomach location ( $p=0.049$ ) were associated with surgery. Overall survival was significantly shorter in the surgery group than in the re-ESD group after treatment for MGC (log-rank test, $\mathrm{p}=0.01$ ). Conclusions: Lower BMI and multiplicity of index cancers were significantly associated with the surgical resection of MGC. Close follow-up is needed to minimize additional treatment for cases at high risk of advanced MGC after ESD for EGC. (Gut Liver 2020;14:190-198)
Key Words: Early gastric cancer; Endoscopic submucosal dissection; Metachronous gastric cancer; Surgery; Survival rate

\section{INTRODUCTION}

Gastric cancer is the fifth most common malignancy and the third leading cause of cancer death in the world. ${ }^{1}$ Endoscopic submucosal dissection (ESD) has been widely used for early gastric cancer (EGC) in Korea and Japan since the late 1990s. However, as endoscopic resection spares the gastric mucosa in patients with EGC, it has a potential risk of metachronous gastric cancer (MGC). ${ }^{3}$

MGC is usually considered as a developed gastric cancer located distant from the initial EGC after 1 year following index ESD. Previous studies have reported the incidence of MGC following endoscopic resection for EGC ranging from 2.7\% to $15.6 \%{ }^{4}$ Because the incidence of MGC increases as time passes, continuing surveillance is necessary for the detection of MGC even after curative ESD. ${ }^{5}$

Treatment modality for MGC, surgery or re-ESD, is generally determined by the same indications of index EGC. Previous study has reported that $90.3 \%$ of patients with MGC received re-ESD and 5.9\% received surgery. ${ }^{5}$ However, there has been little data of characteristics of index cancer associated with occurrence of MGC in terms of risk of lymph node (LN) metastasis, and clinical outcomes between re-ESD and surgery group for MGC.

The aim of this study was to evaluate the risk factors and clinical outcomes of MGC between re-ESD and surgery group.

\footnotetext{
Correspondence to: Sang Gyun Kim

Division of Gastroenterology, Department of Internal Medicine and Liver Research Institute, Seoul National University College of Medicine, 101 Daehakno, Jongno-gu, Seoul 03080, Korea

Tel: +82-2-740-8112, Fax: +82-2-743-6701, E-mail: harley1333@hanmail.net

Received on December 27, 2018. Revised on February 13, 2019. Accepted on April 4, 2019. Published online November 11, 2019. pISSN 1976-2283 eISSN 2005-1212 https://doi.org/10.5009/gnl18575

(a) This is an Open Access article distributed under the terms of the Creative Commons Attribution Non-Commercial License (http://creativecommons.org/licenses/by-nc/4.0) which permits unrestricted non-commercial use, distribution, and reproduction in any medium, provided the original work is properly cited.
} 


\section{MATERIALS AND METHODS}

\section{Patients}

Patients who had undergone ESD for gastric neoplasms and been diagnosed as EGC in final pathology from January 2005 through May 2014 at Seoul National University Hospital were retrospectively reviewed. Indications for ESD were as follows: biopsy-proven adenoma, and differentiated adenocarcinoma with gross tumor size $\leq 2 \mathrm{~cm}$ and no evidence of submucosal invasion or metastasis to LNs or other distant organ. Curative resection was defined as an en bloc resection with tumornegative margin, without evidence of lympho-vascular invasion, and within the expanded criteria. Expanded criteria were defined as follows: (1) differentiated mucosal cancer without ulcer regardless of size; (2) differentiated mucosal cancer $\leq 3 \mathrm{~cm}$ with ulcer; (3) undifferentiated mucosal cancer $\leq 2 \mathrm{~cm}$; or (4) differentiated submucosal (SM) 1 (tumor invasion $<500 \mu \mathrm{m}$ from the muscularis mucosa) cancer $\leq 3 \mathrm{~cm} .{ }^{6}$ In the cases of non-curative resection, additional surgical resection was recommended in principle, which might be waived in exceptional cases with underlying severe co-morbidity, old age ( $>80$ years), or patients' preference. MGC was defined as a newly developed cancer at other site from index cancer in stomach beyond 1 year after index ESD, and included both metachronous EGC and advanced gastric cancer (AGC). ESD indications for MGC were applied of the same method as index EGC. Metachronous EGC with noncurative resection and metachronous AGC was treated by sur- gery.

Patients were excluded if they had gastrectomy within 12 months after index ESD or follow-up period less than 12 months. The patients with MGC were divided into two groups; re-ESD and surgery group. Demographic data were achieved from medical records, including age, sex, body mass index (BMI), and pathological data of index cancer and MGC; atrophy, intestinal metaplasia, Helicobacter pylori status, tumor findings (gross type, multiplicity, Lauren type, differentiation, depth of invasion, vertical location, size, presence of ulcer, lympho-vascular invasion, and resection margin). The Institutional Review Board of the Seoul National University Hospital approved this study (IRB number: H1612-103-815). Patient consent was waived, given the retrospective nature of this study.

\section{Methods of ESD, pathologic evaluation and endoscopic follow-up}

All ESD procedures were performed using a standard singlechannel endoscope (Olympus H260; Olympus Optical, Tokyo, Japan), as previously described. ${ }^{7}$ Briefly, after marking at 5-mm outside of the lesion, circumferential incision was done outside the marking and dissection was performed beneath submucosal layer using an insulation-tipped knife (Helmet Snare; Kachu Technology Co., Seoul, South Korea).

The specimens were evaluated with sections of 2- and 4-mm thickness after ESD and surgical resection, respectively, stained with hematoxylin and eosin. Histologic evaluation was per-

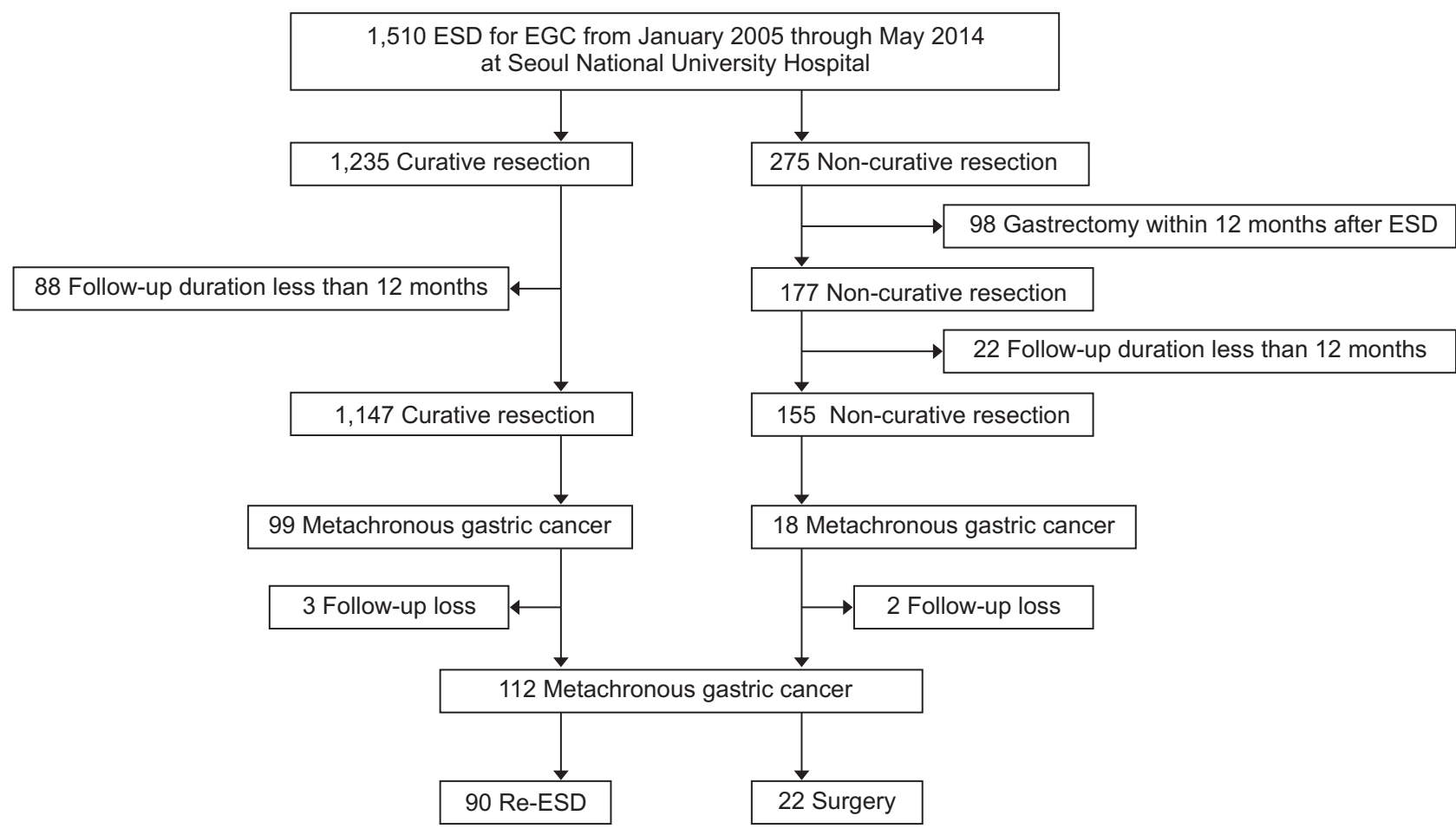

Fig. 1. Study flowchart showing patient enrollment.

ESD, endoscopic submucosal dissection; EGC, early gastric cancer. 
formed from the antrum and body in terms of $H$. pylori status, mucosal atrophy/intestinal metaplasia both at the diagnosis of index cancer and MGC. Histological grades of mucosal atrophy and intestinal metaplasia were reported using the Updated Sydney System. The scores were defined as normal (0), mild (1), moderate (2), and marked (3), and moderate and marked grade were defined as positive. Rapid urease test (CLOtest ${ }^{\circledR}$; Delta West Ltd., Bentley, Australia) was also conducted at antrum, and $H$. pylori status was judged as positive if histologic and/or rapid urease test was positive.

Follow-up endoscopies after ESD were scheduled at 3, 6, 12 months, and annually thereafter. On the other hand, follow-up endoscopies after surgery were conducted annually. The followup period was calculated as the interval between index ESD/ treatment for MGC and the last endoscopic follow-up.

Overall survival (OS) was defined as the period from the date of ESD/surgery for MGC until all death.

\section{Statistical analysis}

Re-ESD and surgery group were compared for demographic and clinicopathological data using the Pearson chi-square test, Fisher exact test, Mann-Whitney U test, Student t-test, and logistic regression model. Multivariate analysis included statistically significant $(\mathrm{p}<0.05)$ and clinically important covariates in the univariate analysis using the logistic regression model. The cumulative incidences of metachronous carcinoma were calculated using the Kaplan-Meier method with a log-rank test. All statistics were analyzed using the Statistical Package for the Social Sciences, version 19.0 (SPSS Inc., Chicago, IL, USA).

\section{RESULTS}

1. Study population and cumulative incidence of MGC occurrence

A total of 1,510 patients who had undergone ESD for EGC from January 2005 through May 2014 at Seoul National University Hospital were included in this retrospective cohort study, of whom 208 patients were excluded; 98 patients with gastrectomy within 12 months after ESD, and 110 patients lost to follow-up within 12 months after ESD.

In 1,302 eligible patients, curative resection was achieved in 1,147 , and non-curative resection in 155 . The mean follow-up duration was $66 \pm 30$ months (range, 12 to 156 months). During follow-up period, MGC had developed in 117 patients (9\%), of whom 90 patients underwent re-ESD, 22 surgery, and five lost to further treatment. In the surgery group, three patients had received additional surgical resection after re-ESD by the final result of pathological mapping beyond expanded indication (Fig. 1).

In the Kaplan-Meier analysis, the median duration to MGC development was 47 months (interquartile range, 30 to 67 months), which gradually increased as time passed (Fig. 2A). There was no significant difference in the cumulative incidence of MGC between curative resection and non-curative resection group ( $\mathrm{p}=0.221$ in log-rank test) (Fig. 2B)

\section{Clinicopathological characteristics of index cancer af- fecting treatment for MGC}

Males were predominant in both groups; re-ESD (74/90, $82.2 \%)$ and surgery $(17 / 22,77.3 \%)$ (Table 1$)$. Patients in re-ESD group had significantly higher BMI $(\mathrm{p}=0.025)$ and moderate to severe intestinal metaplasia $(\mathrm{p}=0.029)$ than surgery group However, there were no significant differences in other index clinicopathological characteristics between surgery and re-ESD
A

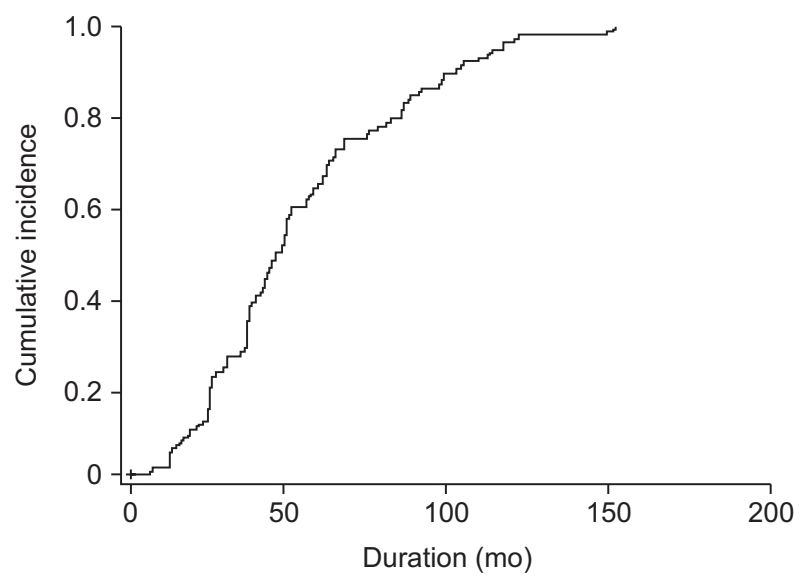

B

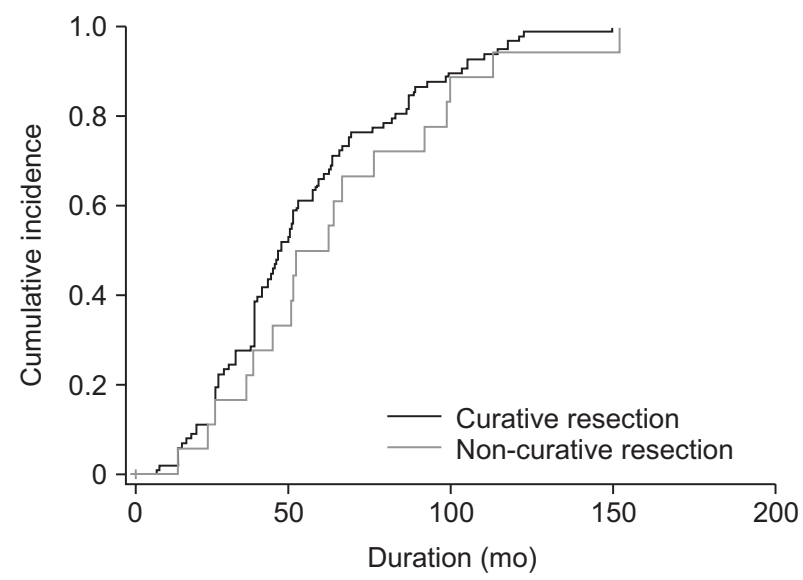

Fig. 2. Cumulative incidence of metachronous gastric cancer (MGC) after endoscopic submucosal dissection (ESD). (A) Cumulative incidence of MGC after ESD and (B) cumulative incidence of MGC after ESD (curative resection versus noncurative resection). 
Table 1. Baseline and Index Tumor Characteristics of the Re-ESD and Surgery Groups

\begin{tabular}{|c|c|c|c|c|}
\hline Baseline and index tumor characteristics & Overall $(n=112)$ & Re-ESD $(n=90)$ & Surgery $(n=22)$ & p-value \\
\hline \multicolumn{5}{|l|}{ Clinical characteristics } \\
\hline Age, yr & $64.5 \pm 9.5$ & $64.7 \pm 9.6$ & $63.6 \pm 8.9$ & 0.596 \\
\hline Sex male & $91(81.3)$ & $74(82.2)$ & 17 (77.3) & 0.594 \\
\hline BMI, $\mathrm{kg} / \mathrm{m}^{2}$ & $24.5 \pm 2.7$ & $24.7 \pm 2.7$ & $23.3 \pm 2.4$ & 0.025 \\
\hline \multicolumn{5}{|l|}{ Pathologic characteristics at index cases } \\
\hline Index $H$. pylori infection & & & & 0.242 \\
\hline Positive & $58(51.8)$ & $49(54.4)$ & $9(40.9)$ & \\
\hline Negative & $44(39.3)$ & $32(35.6)$ & $12(54.5)$ & \\
\hline Atrophy* & & & & 0.891 \\
\hline Moderate to marked & $43(38.4)$ & 35 (38.9) & $8(36.4)$ & \\
\hline Absent to mild & $46(41.1)$ & $36(40)$ & $10(45.5)$ & \\
\hline Intestinal metaplasia & & & & 0.029 \\
\hline Moderate to marked & 79 (70.5) & $67(74.4)$ & $12(54.5)$ & \\
\hline Absent to mild & $23(20.5)$ & $14(15.6)$ & $9(40.9)$ & \\
\hline Gross type & & & & 0.754 \\
\hline Elevated & $44(39.3)$ & $36(40)$ & $8(36.4)$ & \\
\hline Non-elevated & $68(60.7)$ & $54(60)$ & 14 (63.6) & \\
\hline Multiple cancer & & & & 0.09 \\
\hline One & $102(91.1)$ & 84 (93.3) & $18(81.8)$ & \\
\hline Multiple (>1) & $10(8.9)$ & $6(6.7)$ & $4(18.2)$ & \\
\hline Lauren type & & & & 0.054 \\
\hline Intestinal & $106(94.6)$ & $87(96.7)$ & 19 (86.4) & \\
\hline Diffuse or mixed & $6(5.4)$ & $3(3.3)$ & 3 (13.6) & \\
\hline Differentiation type & & & & 0.054 \\
\hline Differentiated & $106(94.6)$ & 87 (96.7) & $19(86.4)$ & \\
\hline Undifferentiated & $6(5.4)$ & $3(3.3)$ & $3(13.6)$ & \\
\hline Depth & & & & 0.147 \\
\hline $\mathrm{T} 1 \mathrm{~m}$ & $104(92.8)$ & $83(92.2)$ & $22(100)$ & \\
\hline T1sm & $8(7.2)$ & 7 (7.7) & 0 & \\
\hline Tumor location & & & & 0.424 \\
\hline Upper & 4 (3.6) & $4(4.4)$ & 0 & \\
\hline Middle & $27(24.1)$ & $23(25.6)$ & $4(18.2)$ & \\
\hline Lower & $81(72.3)$ & $63(70)$ & $18(81.8)$ & \\
\hline Tumor size, mm & $1.9 \pm 1.2$ & $18.5 \pm 10.6$ & $19.5 \pm 11.2$ & 0.538 \\
\hline Ulcer* & & & & 0.527 \\
\hline Yes & $3(2.7)$ & $3(3.3)$ & 0 & \\
\hline No & $107(95.5)$ & $85(94.4)$ & $22(100)$ & \\
\hline Venous invasion & & & & - \\
\hline Yes & 0 & 0 & 0 & \\
\hline No & $112(100)$ & $90(80.4)$ & 22 (19.6) & \\
\hline Lymphatic invasion & & & & 0.48 \\
\hline Yes & $2(1.8)$ & $2(2.2)$ & 0 & \\
\hline No & $110(98.2)$ & 88 (97.8) & $22(20)$ & \\
\hline
\end{tabular}


Table 1. Continued

\begin{tabular}{|c|c|c|c|c|}
\hline Baseline and index tumor characteristics & Overall $(\mathrm{n}=112)$ & Re-ESD $(n=90)$ & Surgery $(n=22)$ & p-value \\
\hline Vertical resection margin & & & & 0.276 \\
\hline Positive & $2(1.8)$ & $1(1.1)$ & $1(4.5)$ & \\
\hline Negative & $110(98.2)$ & $89(98.9)$ & $21(95.5)$ & \\
\hline Curative resection & & & & 0.923 \\
\hline Yes & $96(85.7)$ & $77(85.6)$ & $19(86.4)$ & \\
\hline No & $16(14.3)$ & $13(14.4)$ & $3(13.6)$ & \\
\hline $\begin{array}{l}\text { Duration from index ESD to diagnosis of } \\
\text { metachronous cancer, mo }\end{array}$ & $53.8 \pm 31.3$ & $53.0 \pm 30.6$ & $56.9 \pm 34.4$ & 0.698 \\
\hline
\end{tabular}

Data are presented as mean \pm SD or number (\%).

ESD, endoscopic submucosal dissection; BMI, body mass index; H. pylori, Helicobacter pylori; m, mucosal cancer; sm, submucosal cancer.

*Exception where pathologic evaluation is inapplicable or medical record is absent.

Table 2. Multivariate Analysis of the Baseline and Index Tumor Characteristics in the Re-ESD and Surgery Groups

\begin{tabular}{lccc}
\hline \multicolumn{1}{c}{ Baseline and index tumor characteristics } & p-value & Exp (B) & 95\% CI for Exp (B) \\
\hline BMI & 0.037 & 0.744 & $(0.563-0.983)$ \\
Male sex & 0.552 & & $(1.982-428.465)$ \\
Initial multiple cancer (yes) & 0.014 & 29.131 & \\
Atrophy, index case (moderate to marked) & 0.133 & \\
Intestinal metaplasia, index case (moderate to marked) & 0.226 & \\
Index H. pylori infection (positive) & 0.971 & & \\
Differentiation type (undifferentiated) & 0.751 & \\
\hline
\end{tabular}

ESD, endoscopic submucosal dissection; CI, confidence interval; BMI, body mass index; H. pylori, Helicobacter pylori.

groups for MGC. The median period to MGC occurrence after ESD was not associated with the type of treatment for MGC $(p=0.698)$.

In multivariate analysis, lower BMI and multiplicity of index cases were significantly associated with surgery than reESD group (odds ratio [OR], 0.744; 95\% confidence interval [CI], 0.563 to $0.983 ; \mathrm{p}=0.037$ and $\mathrm{OR}, 29.131 ; 95 \% \mathrm{CI}, 1.982$ to 428.465; $\mathrm{p}=0.014$, respectively) (Table 2).

\section{Treatment outcomes and prognosis of MGC between re- ESD versus surgery group}

To compare the treatment outcomes of re-ESD with surgery group, we analyzed pathologic features of MGC of both groups. In surgery group, tumors invaded to proper muscle and over in four cases (18.1\%). Tumor invasion to lymphatics was found in $13.6 \%$ of surgery and $4.4 \%$ of re-ESD group. In surgery group, tumors had LN metastasis in $22.7 \%$. In univariate analysis, persistent $H$. pylori infection, intestinal type, differentiated histology, mucosal cancer, middle or lower location of stomach, and smaller tumor size were more common in re-ESD than surgery group (Table 3). In multivariate analysis, non-intestinal type, tumor invasion over mucosa, and upper location of stomach were more common in surgery than re-ESD group (Table 4). Persistent $H$. pylori infection was not associated with re-ESD or surgery group.
A total of seven patients of 112 patients (6.3\%) died during a mean follow-up period of $66 \pm 30$ months. Mortality rate was higher in surgery (22.7\%) than re-ESD group (2.2\%), and OS was significantly higher in re-ESD than surgery group $(p=0.01$, log-rank test) (Fig. 3).

\section{DISCUSSION}

ESD has been regarded as the standard treatment for EGC in proper indication, and has a strong merit in terms of preservation of organ and maintenance of quality of life. Nevertheless, concerns about MGC still remain because the remnant gastric mucosa also has the risk of new tumor development even after endoscopic resection for EGC. ${ }^{4}$ The incidence of MGC after endoscopic resection has been reported to be $5.1 \%$ to $14 \% .{ }^{8,9}$ In this study, MGC occurred in 9\% during the median follow up of 66 months, which was similar to previous studies. Cumulative incidence of MGC had increased over time from 9.5\% in 5 years to $22.7 \%$ in 10 years. ${ }^{5}$ The present study showed that the median time interval to MGC was 47 months, and the incidence of MGC had gradually increased up to 10 years, which suggests that endoscopic surveillance may be important for more than 10 years after endoscopic resection of EGC.

This retrospective study has strength in that it compared the index characteristics of two groups; re-ESD and surgery groups 
Table 3. Treatment Outcomes of Re-ESD versus Surgery for MGC: Univariate analysis for the Pathological Features of Metachronous Cancer

\begin{tabular}{|c|c|c|c|c|}
\hline Pathologic characteristics & Overall $(n=112)$ & Re-ESD $(\mathrm{n}=90)$ & Surgery $(n=22)$ & $\mathrm{p}$-value \\
\hline Persistent $H$. pylori infection & & & & 0.047 \\
\hline Negative or eradicated & $50(44.6)$ & $38(42.2)$ & $12(54.5)$ & \\
\hline Persistent & $40(35.7)$ & $37(41.1)$ & $3(13.6)$ & \\
\hline Unknown & $22(19.6)$ & 15 (16.7) & $7(31.8)$ & \\
\hline Atrophy & & & & 0.774 \\
\hline Moderate to severe & $25(22.5)$ & $22(24.4)$ & $3(13.6)$ & \\
\hline Absent to mild & $40(36)$ & $37(41.2)$ & $4(18.1)$ & \\
\hline Intestinal metaplasia & & & & 0.594 \\
\hline Moderate to severe & 57 (51.3) & $51(56.7)$ & $6(27.3)$ & \\
\hline Absent to mild & $20(17.9)$ & $17(18.9)$ & $3(13.6)$ & \\
\hline Gross type & & & & 0.976 \\
\hline Elevated & $10(8.9)$ & $8(8.9)$ & $2(9.1)$ & \\
\hline Non-elevated & $102(91.1)$ & $82(91.1)$ & 20 (90.9) & \\
\hline Multiple cancer & & & & 0.394 \\
\hline One & $102(91.1)$ & $83(92.2)$ & $19(86.4)$ & \\
\hline Multiple (>1) & $10(8.9)$ & $7(7.8)$ & $3(13.6)$ & \\
\hline Lauren type* & & & & $<0.001$ \\
\hline Intestinal & $81(85.4)$ & $72(87.8)$ & $10(50)$ & \\
\hline Diffuse or mixed & $14(14.6)$ & $4(28.6)$ & $10(50)$ & \\
\hline Differentiation type & & & & $<0.001$ \\
\hline Differentiated & $96(85.7)$ & $85(94.4)$ & $11(50)$ & \\
\hline Undifferentiated & $16(14.3)$ & $5(5.6)$ & $11(50)$ & \\
\hline Depth & & & & 0.001 \\
\hline $\mathrm{T} 1 \mathrm{~m}$ & 88 (78.6) & 77 (85.6) & $14(63.7)$ & \\
\hline$\geq \mathrm{T} 1 \mathrm{sm}$ & $24(21.4)$ & $13(14.4)$ & 8 (36.3) & \\
\hline Tumor location & & & & 0.038 \\
\hline Upper & $8(7.1)$ & $4(4.4)$ & $4(18.2)$ & \\
\hline Middle or lower & $104(92.9)$ & 86 (95.6) & $18(81.8)$ & \\
\hline Tumor size, mm & $19.7 \pm 1.3$ & $18 \pm 1$ & $26.8 \pm 2$ & 0.012 \\
\hline Ulcer $^{\dagger}$ & & & & $<0.05$ \\
\hline Yes & $1(0.9)$ & $1(1.1)$ & 0 & \\
\hline No & $92(82.1)$ & 89 (98.9) & $10(45.5)$ & \\
\hline Venous invasion & & & & 0.999 \\
\hline Yes & $1(0.9)$ & 0 & $1(4.5)$ & \\
\hline No & $111(99.1)$ & $90(100)$ & $21(95.5)$ & \\
\hline Lymphatic invasion & & & & 0.129 \\
\hline Yes & $7(6.3)$ & $4(4.4)$ & $3(13.6)$ & \\
\hline No & $105(5.4)$ & 86 (95.6) & $19(86.4)$ & \\
\hline Lymph node metastasis & & & & - \\
\hline Positive & - & - & $5(22.7)$ & \\
\hline Negative & - & - & $17(77.3)$ & \\
\hline Vertical resection margin & & & & 0.999 \\
\hline Positive & $5(4.5)$ & $5(5.6)$ & 0 & \\
\hline Negative & $104(92.9)$ & 84 (93.3) & 20 (90.6) & \\
\hline Unknown & $3(2.7)$ & $1(5.6)$ & $2(9.1)$ & \\
\hline
\end{tabular}


Table 3. Continued

\begin{tabular}{|c|c|c|c|c|}
\hline Pathological characteristics & Overall $(n=112)$ & Re-ESD $(n=90)$ & Surgery $(n=22)$ & p-value \\
\hline Lateral resection margin & & & & 0.37 \\
\hline Positive & $11(9.8)$ & $10(11.1)$ & $1(4.5)$ & \\
\hline Negative & $101(90.2)$ & $80(88.9)$ & $21(95.5)$ & \\
\hline
\end{tabular}

Data are presented as number $(\%)$ or mean \pm SD.

ESD, endoscopic submucosal dissection; MGC, metachronous gastric cancer; $H$. pylori, Helicobacter pylori.

*Exception where pathologic reports are unknown or indeterminate; ${ }^{\dagger}$ Exception where pathologic evaluation is inapplicable or medical record is absent.

Table 4. Treatment Outcomes of Re-ESD versus Surgery for MGC: Multivariate Analysis for the Pathological Features of Metachronous Cancer

\begin{tabular}{|c|c|c|c|}
\hline Pathological characteristics & p-value & $\operatorname{Exp}(B)$ & 95\% CI for $\operatorname{Exp}(\mathrm{B})$ \\
\hline Persistent $H$. pylori infection & 0.055 & 0.163 & $(0.026-1.038)$ \\
\hline Lauren type (non-intestinal type) & 0.009 & 11.176 & $(1.842-67.792)$ \\
\hline Differentiation (undifferentiated) & - & & \\
\hline Depth of invasion ( $\geq \mathrm{T} 1 \mathrm{sm}$ ) & 0.001 & 19.864 & $(3.329-118.506)$ \\
\hline Tumor location (middle or lower part of stomach) & 0.049 & 0.088 & $(0.008-0.991)$ \\
\hline Tumor size & 0.206 & & \\
\hline
\end{tabular}

ESD, endoscopic submucosal dissection; MCG, metachronous gastric cancer; CI, confidence interval; H. pylori, Helicobacter pylori; sm, submucosal cancer.

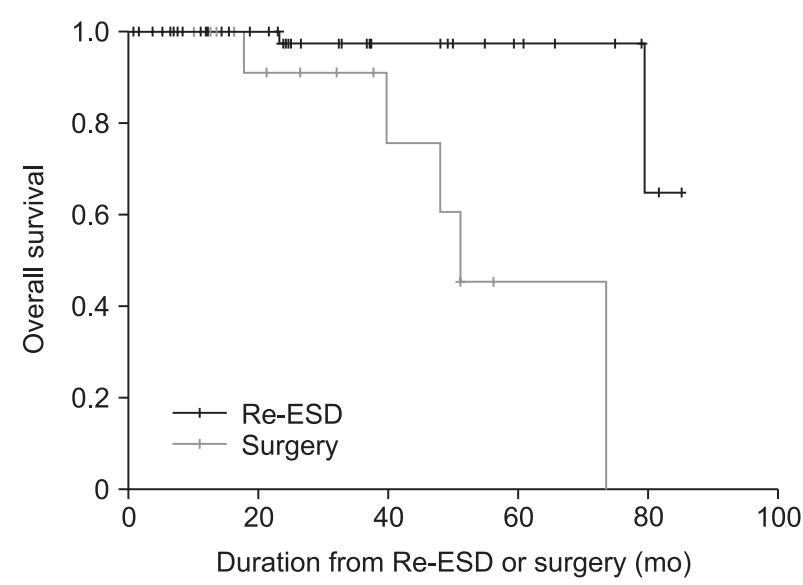

Fig. 3. Overall survival after re-ESD or surgery for metachronous gastric cancer: re-ESD versus surgery groups.

ESD, endoscopic submucosal dissection.

for MGC. Clinicopathological characteristics of index tumor may influence on the development and treatment strategy of MGC. As the treatment of MGC was decided by the endoscopic and histologic characteristics itself, MGC with high risk of LN metastasis was preferentially allocated into surgery group. Therefore, it is important to identify the factors of index tumor that influenced the characteristics of MGC and the subsequent treatment. In addition, these relevant characteristics of index tumor might reflect the development of MGC in terms of the risk of LN metastasis.

Endoscopic resection has been applied to multiple EGCs meeting indications for endoscopic resection. ${ }^{10}$ Multiple gastric cancers tend to be more susceptible to the development of MGC than solitary gastric cancers. ${ }^{5}$ Previous studies have reported that microsatellite instability was related with tumor multiplicity and might be an indicator for the occurrence of metachronous cancer. ${ }^{11}$ However, there has been a debate whether microsatellite instability was associated with tumor aggressiveness and prognosis. ${ }^{12,13}$ In a previous study, multiple EGCs had similar incidence of LN metastasis as solitary cancer. ${ }^{10}$ In this study, index multiple cancer was significantly associated with advanced histology of MGC, eventually surgery group (OR, 29.131; 95\% CI, 1.982 to $428.465 ; \mathrm{p}=0.014)$. Meticulous follow-up may be essential to screen MGC in early stage in cases with initial multiple cancer.

It has been known that obesity is associated with gastric cancer, especially cardia cancer. ${ }^{14}$ However, confounding variables such as $H$. pylori infection were not corrected in the study. In a recent study, obesity increased the risk of well or moderately differentiated EGC regardless of $H$. pylori infection. ${ }^{15}$ In another study, obesity was significantly associated with the risk of noncardia gastric cancer. ${ }^{15,16}$ In this study, BMI was significantly higher in re-ESD than surgery group (OR, 0.744; 95\% CI, 0.563 to $0.983 ; \mathrm{p}=0.037$ ), which showed similar result with previous studies in that higher BMI was significantly associated with less aggressive histology of MGC.

H. pylori infection has been known to be a risk factor of MGC development. ${ }^{17,18}$ In multivariate analysis, $H$. pylori infection, mucosal atrophy, and intestinal metaplasia of index cases were not different between re-ESD and surgery group (Table 2). $H$. pylori infection triggers to precancerous lesions such as atro- 
phic gastritis and intestinal metaplasia. The carcinogenesis from precancerous lesions may progress by cellular adaptive mechanisms including endoplasmic reticulum stress, unfolded protein response, autophagy, oxidative stress, inflammation, epithelialto-mesenchymal transition regardless of persistent $H$. pylori infection. ${ }^{19-23}$ The result that $H$. pylori infection in index cases was not associated with the decision of treatment strategy of MGC in this study may suggest that these cascade and accumulation of epigenetic alteration might be more important in terms of invasiveness of MGC.

It has been well known that $H$. pylori eradication prevented MGC development. ${ }^{17,24,25}$ However, there were few studies about the relationship between persistent $H$. pylori infection and invasiveness of MGC. Although final status of $H$. pylori infection was unknown in some cases in this study and did not have statistical significance in the relationship with advanced MGC, persistent $H$. pylori infection tended to be more frequent in reESD group. Some studies have reported that $H$. pylori infection was more related to intestinal type gastric cancer than diffuse type, ${ }^{26,27}$ which implied that persistent $H$. pylori infection might be associated with re-ESD group rather than surgery group by slow tumor progression.

Multivariate analysis for the treatment outcome of MGC showed that depth of tumor invasion over mucosa, upper location of stomach, diffuse or mixed type were associated with surgery group. Diffuse or mixed type has been known to have aggressive characteristics such as LN spread. In a previous study, epithelial-to-mesenchymal transition-related tumors were generally diffuse type, which were usually diagnosed at advanced stage and had the worst prognosis. ${ }^{28}$ On the other hand, undifferentiated histology was not related to MGC with high risk of LN metastasis. In a recent study, pure histology of poorly cohesive carcinoma showed higher risk of deeper tumor invasion and lymphovascular/perineural invasion than heterogenic histology. ${ }^{29}$ In this study, heterogeneity of undifferentiated histology might not affect the invasiveness and treatment strategy of MGC.

MGC was more frequent in the upper third location in surgery than re-ESD group, where the tumor has been reported to be more invasive and have poorer prognosis. ${ }^{29}$ Lymphovascular/ perineural invasion was known as the indicators to poor prognosis of gastric cancer. A previous study has reported that gastric cancer with perineural invasion was associated with diffusemixed Lauren type and upper third location, ${ }^{30}$ where tumor cells might easily spread out the gap between the large autonomic nerves and tissues.

The OS from treatment of MGC was significantly higher in reESD than surgery group. Mean follow-up duration of $24.8 \pm 19.5$ months from the treatment for MGC was too short to compare disease free survival after MGC between the groups. Although we could only confirm OS of the groups, there was a the possibility that the gastric cancer-related death might be higher in the surgery group by significant higher mortality rate. Since curative resection rate of re-ESD did not differ from surgery ( $p>0.05$ ), the presence of LN metastasis might influence on prognosis of MGC.

This study has several limitations. As a single center retrospective study, there might be selection or information biases. Surgery group might show poor OS because MGC with high risk of LN metastasis was recommended to undergo surgical resection rather than re-ESD. Although exact LN metastasis in reESD group could not be evaluated without surgical evaluation including LN dissection, it might be postulated that higher OS was achieved during long-term follow-up without tumor recurrence from LN or distant metastasis in the re-ESD group in spite of similar rate of curative resection in both groups. $H$. pylori status was also unclear in many patients during follow-up. Although there was sufficient follow-up duration after index EGC, the number of MGC might be too small to evaluate the strong relationship between risk factors and MGC with LN metastasis.

In conclusion, lower BMI and multiplicity of index cancer were significantly related to subsequent MGC with high risk of LN metastasis. Close follow-up is mandatory for the patients with the risks to minimize the additional treatment for MGC after index ESD.

\section{CONFLICTS OF INTEREST}

No potential conflict of interest relevant to this article was reported.

\section{ACKNOWLEDGEMENTS}

This work was supported by a grant (NRF-2017R1D1A1B030 36304) of the Basic Science Research Program through the National Research Foundation (NRF) funded by the Ministry of Education, Republic of Korea.

\section{AUTHOR CONTRIBUTIONS}

Data analysis and writing - original draft: J.L.K. Study design: H.C. Writing - review and editing: H.C., S.G.K. Advice on the study design: S.G.K. Statistical support and data acquisition: J.K., J.Y.P., H.J.Y., H.J.K. All authors have read and approved the manuscript.

\section{ORCID}

Jue Lie Kim

Sang Gyun Kim

Jung Kim

Jae Yong Park

Hyo-Joon Yang

Hyun Ju Kim

Hyunsoo Chung https://orcid.org/0000-0002-2371-9646 https://orcid.org/0000-0003-1799-9028 https://orcid.org/0000-0001-9509-0851 https://orcid.org/0000-0001-6114-8920 https://orcid.org/0000-0002-0265-672X https://orcid.org/0000-0002-4406-7552 https://orcid.org/0000-0001-5159-357X 


\section{REFERENCES}

1. Ferlay J, Soerjomataram I, Dikshit R, et al. Cancer incidence and mortality worldwide: sources, methods and major patterns in GLOBOCAN 2012. Int J Cancer 2015;136:E359-E386.

2. Nishizawa T, Yahagi N. Long-term outcomes of using endoscopic submucosal dissection to treat early gastric cancer. Gut Liver 2018;12:119-124.

3. Asada K, Nakajima T, Shimazu T, et al. Demonstration of the usefulness of epigenetic cancer risk prediction by a multicentre prospective cohort study. Gut 2015;64:388-396.

4. Abe S, Oda I, Minagawa T, et al. Metachronous gastric cancer following curative endoscopic resection of early gastric cancer. Clin Endosc 2018;51:253-259.

5. Abe S, Oda I, Suzuki H, et al. Long-term surveillance and treatment outcomes of metachronous gastric cancer occurring after curative endoscopic submucosal dissection. Endoscopy 2015;47: 1113-1118.

6. Park JY, Kim SG, Kim J, et al. Risk factors for early metachronous tumor development after endoscopic resection for early gastric cancer. PLoS One 2017;12:e0185501.

7. Yoon H, Kim SG, Choi J, et al. Risk factors of residual or recurrent tumor in patients with a tumor-positive resection margin after endoscopic resection of early gastric cancer. Surg Endosc 2013;27: 1561-1568.

8. Han JS, Jang JS, Choi SR, et al. A study of metachronous cancer after endoscopic resection of early gastric cancer. Scand J Gastroenterol 2011;46:1099-1104.

9. Lee HJ, Lee YJ, Lee JY, et al. Characteristics of synchronous and metachronous multiple gastric tumors after endoscopic submucosal dissection of early gastric neoplasm. Clin Endosc 2018;51:266273.

10. Choi J, Kim SG, Im JP, et al. Lymph node metastasis in multiple synchronous early gastric cancer. Gastrointest Endosc 2011;74: 276-284.

11. Yasui W, Oue N, Aung PP, Matsumura S, Shutoh M, Nakayama $\mathrm{H}$. Molecular-pathological prognostic factors of gastric cancer: a review. Gastric Cancer 2005;8:86-94.

12. Choi SW, Choi JR, Chung YJ, Kim KM, Rhyu MG. Prognostic implications of microsatellite genotypes in gastric carcinoma. Int $\mathrm{J}$ Cancer 2000;89:378-383.

13. Wirtz HC, Müller W, Noguchi T, et al. Prognostic value and clinicopathological profile of microsatellite instability in gastric cancer. Clin Cancer Res 1998;4:1749-1754.

14. Calle EE, Kaaks R. Overweight, obesity and cancer: epidemiological evidence and proposed mechanisms. Nat Rev Cancer 2004;4: 579-591.

15. Kim HJ, Kim N, Kim HY, et al. Relationship between body mass index and the risk of early gastric cancer and dysplasia regardless of Helicobacter pylori infection. Gastric Cancer 2015;18:762-773.

16. Levi Z, Kark JD, Twig G, et al. Body mass index at adolescence and risk of noncardia gastric cancer in a cohort of 1.79 million men and women. Cancer 2018;124:356-363.

17. Choi IJ, Kook MC, Kim YI, et al. Helicobacter pylori therapy for the prevention of metachronous gastric cancer. N Engl J Med 2018; 378:1085-1095.

18. Choi JM, Kim SG, Choi J, et al. Effects of Helicobacter pylori eradication for metachronous gastric cancer prevention: a randomized controlled trial. Gastrointest Endosc 2018;88:475-485.

19. Díaz P, Valenzuela Valderrama M, Bravo J, Quest AFG. Helicobacter pylori and gastric cancer: adaptive cellular mechanisms involved in disease progression. Front Microbiol 2018;9:5.

20. Yang Y, Li X, Du J, Yin Y, Li Y. Involvement of microRNAsMMPs-E-cadherin in the migration and invasion of gastric cancer cells infected with Helicobacter pylori. Exp Cell Res 2018;367:196204.

21. Yang HJ, Kim SG, Lim JH, Choi JM, Kim WH, Jung HC. Helicobacter pylori-induced modulation of the promoter methylation of Wnt antagonist genes in gastric carcinogenesis. Gastric Cancer 2018;21:237-248.

22. Lim JH, Kim SG, Choi JM, Yang HJ, Kim JS, Jung HC. Helicobacter pylori is associated with miR-133a expression through promoter methylation in gastric carcinogenesis. Gut Liver 2018;12:58-66.

23. Maeda M, Yamashita S, Shimazu T, et al. Novel epigenetic markers for gastric cancer risk stratification in individuals after Helicobacter pylori eradication. Gastric Cancer 2018;21:745-755.

24. Nakajima T, Enomoto S, Yamashita S, et al. Persistence of a component of DNA methylation in gastric mucosae after Helicobacter pylori eradication. J Gastroenterol 2010;45:37-44.

25. Xiao S, Li S, Zhou L, Jiang W, Liu J. Helicobacter pylori status and risks of metachronous recurrence after endoscopic resection of early gastric cancer: a systematic review and meta-analysis. J Gastroenterol 2019;54:226-237.

26. Conteduca V, Sansonno D, Lauletta G, Russi S, Ingravallo G, Dammacco F. H. pylori infection and gastric cancer: state of the art (review). Int J Oncol 2013;42:5-18.

27. Strong VE. Progress in gastric cancer. Updates Surg 2018;70:157159.

28. Cristescu R, Lee J, Nebozhyn M, et al. Molecular analysis of gastric cancer identifies subtypes associated with distinct clinical outcomes. Nat Med 2015;21:449-456.

29. Kwon CH, Kim YK, Lee S, et al. Gastric poorly cohesive carcinoma: a correlative study of mutational signatures and prognostic significance based on histopathological subtypes. Histopathology 2018;72:556-568.

30. De Franco L, Marrelli D, Voglino C, et al. Prognostic value of perineural invasion in resected gastric cancer patients according to Lauren histotype. Pathol Oncol Res 2018;24:393-400. 